\title{
Challenges in pulmonary fibrosis - 3: Cystic lung disease
}

\author{
Gregory P Cosgrove, Stephen K Frankel, Kevin K Brown
}

Thorax 2007;62:820-829. doi: 10.1136/thx.2004.031013

Cystic lung disease is a frequently encountered problem caused by a diverse group of diseases. Distinguishing true cystic lung disease from other entities, such as cavitary lung disease and emphysema, is important given the differing prognostic implications. In this paper the features of the cystic lung diseases are reviewed and contrasted with their mimics, and the clinical and radiographic features of both diffuse (pulmonary Langerhans' cell histiocytosis and lymphangioleiomyomatosis) and focal or multifocal cystic lung disease are discussed.

See end of article for authors' affiliations

\section{Correspondence to:} Dr Kevin K Brown, National Jewish Medical and

Research Center, 1400 Jackson Street, F107. Denver, Colorado 80206,

USA; brownk@njc.org

Received 3 September 2004 Accepted 8 August 2005
$\mathrm{T}$ he identification of air-containing lucencies within the pulmonary parenchyma on radiographic studies is a frequently encountered problem by all those who care for patients with lung disease. The availability of high-resolution computed tomographic (HRCT) scanning, with both its sensitivity and specificity for defining abnormalities of the lung parenchyma, has dramatically improved our ability to characterise these pulmonary lesions. They can be usefully classified as either cysts or cavities, with cysts including subcategories of bullae, blebs and pneumatoceles. While all refer to an air-filled lucency within the lung parenchyma, each denotes a specific radiographic feature that can be differentiated on the basis of wall thickness, size, overall number and anatomical distribution. Why make distinctions among these radiographic features and their patterns? The differential diagnosis possibilities associated with each pattern may differ substantially, such that the evaluation and subsequent management may be fundamentally altered.

Cysts refer to air-filled spaces with sharply demarcated thin walls $(<4 \mathrm{~mm})$ whereas cavities refer to air-filled lesions with thick walls $(>4 \mathrm{~mm})$ (fig 1). ${ }^{1} \mathrm{~A}$ bulla is a cyst $>1 \mathrm{~cm}$ in diameter with a smooth wall $<1 \mathrm{~mm}$ in thickness. ${ }^{1}$ In contrast, blebs are cysts usually $<1 \mathrm{~cm}$ in diameter, subpleural or pleural in location, and typically in an apical distribution. ${ }^{12}$ Pneumatoceles are cysts which accompany primary pulmonary infections or chest trauma and frequently resolve with treatment of the associated infection.

Cysts and cavities must be differentiated from a number of other radiographic features that may mimic them including emphysema, loculated pneumothoraces, honeycomb lung and bronchiectasis (both traction and suppurative). Emphysema differs from cystic lung disease as the term refers to irregular asymmetrical areas of decreased lung attenuation and decreased vascularity (termed "arterial deficiency") which do not have a defined wall (fig 2). ${ }^{34}$ Honeycombing is defined as a cluster or row of cysts that are usually $<5 \mathrm{~mm}$ in diameter and associated with end-stage lung fibrosis. Honeycombing is most often subpleural in distribution and accompanied by other features of lung fibrosis such as reticulation and traction bronchiectasis (fig 3). ${ }^{5}$ Honeycombing may be seen as a result of any disease that results in pulmonary fibrosis. Bronchiectasis, or the dilatation and distortion of bronchi and bronchioles, may be mistaken for cystic airspace disease when a dilated airway is viewed "en face" (fig 3). Bronchiectasis may be the result of either a chronic suppurative process or accompany lung fibrosis, when it is then referred to as traction bronchiectasis. In traction bronchiectasis, bronchi and bronchioles are dilated or stented open as a consequence of increased elastic recoil. ${ }^{6}$ They can be differentiated from cystic lung disease by the presence of an adjacent blood vessel suggesting a bronchovascular unit rather than a cystic air space. Lastly, a loculated pneumothorax may mimic a cystic air space disease, but can be differentiated from true cysts based on its distribution, failure to adhere to a defined anatomical unit and relationship to the pleural surface.

In this paper we review the aetiology, clinical and radiographic characteristics of congenital and acquired cystic lung disease, with a particular focus on two diffuse diseases (pulmonary Langerhans' cell histiocytosis (PLCH) and lymphangioleiomyomatosis (LAM), and two focal or multifocal cystic lung diseases (desquamative interstitial pneumonia (DIP) and lymphocytic interstitial pneumonia (LIP)). We will only briefly review cavitary lung disease, primarily as it contrasts with cystic lung disease, and refer the reader to a recent article by Ryu and Swensen for an in-depth review of this topic.

\section{CAVITARY LUNG DISEASE}

Cavities are thick-walled $(>4 \mathrm{~mm})$ intraparenchymal airspace opacities whose causes are numerous and include congenital, infectious, inflammatory/autoimmune and neoplastic disorders (table 1). Because of prognostic and therapeutic implications of the underlying diagnosis, a definitive evaluation is required.

Of paramount importance is determining whether a lesion is neoplastic, and the thickness of the cavity wall is useful in this regard. Solitary

Abbreviations: AML, angiomyolipoma; CCAM, congenital cystic adenomatoid malformation; DIP, desquamative interstitial pneumonia; $\mathrm{HRCT}$, high resolution computed tomography; LAM, lymphangioleiomyomatosis; LIP, lymphocytic interstitial pneumonia; PLCH, pulmonary Langerhans' cell histiocytosis; TSC, tuberous sclerosis complex 

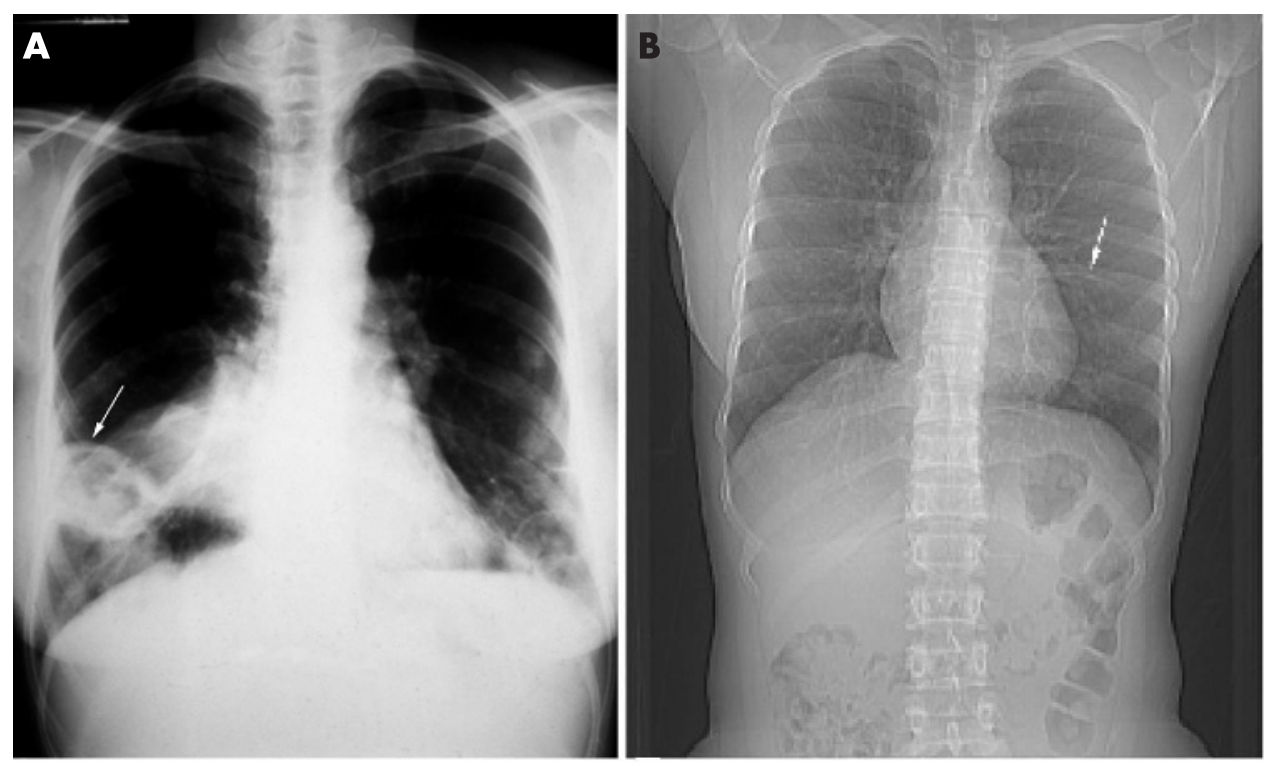

Figure 1 Posteroanterior chest radiographs demonstrating a cavitary lesion (arrow) in Wegener's granulomatosis (A). In contrast, note the thin-walled cyst (arrow) in a patient with Siögren's disease (B). Cavities are defined as air-filled lesions with thick walls $>4 \mathrm{~mm}$ whereas cysts are sharply demarcated thin walls $<4 \mathrm{~mm}$ (C).
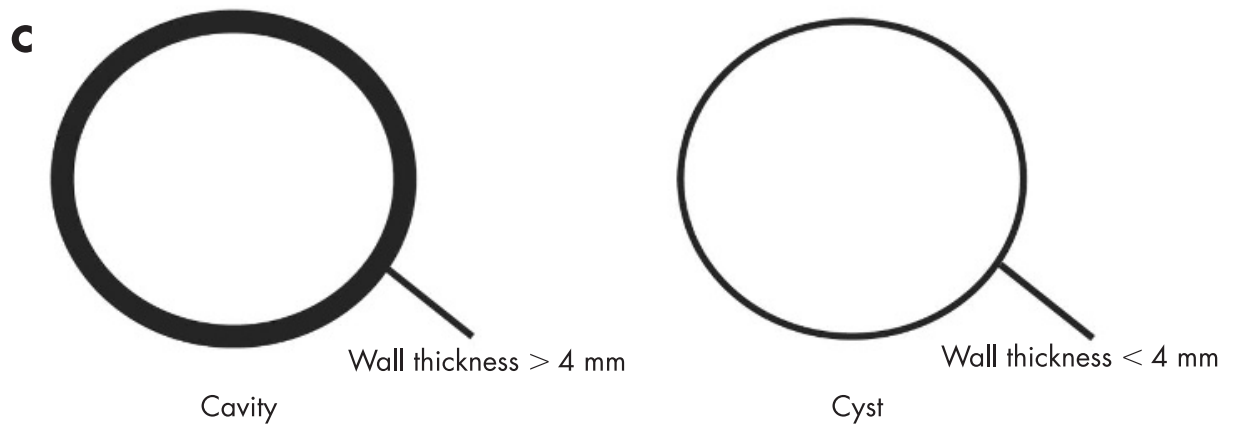

cysts (wall thickness $<4 \mathrm{~mm}$ ) are benign in more than $90 \%$ of cases. ${ }^{8}$ In contrast, solitary cavities with a wall thickness $>15 \mathrm{~mm}$ are malignant $95 \%$ of the time. ${ }^{8}$ Cavities with walls $>5 \mathrm{~mm}$ but $<15 \mathrm{~mm}$ are equally as likely to be malignant as they are benign. Overall, the majority of solitary cavities are neoplastic and represent bronchogenic carcinomas (most commonly squamous cell carcinoma), although rarely pulmonary lymphomas can cavitate.

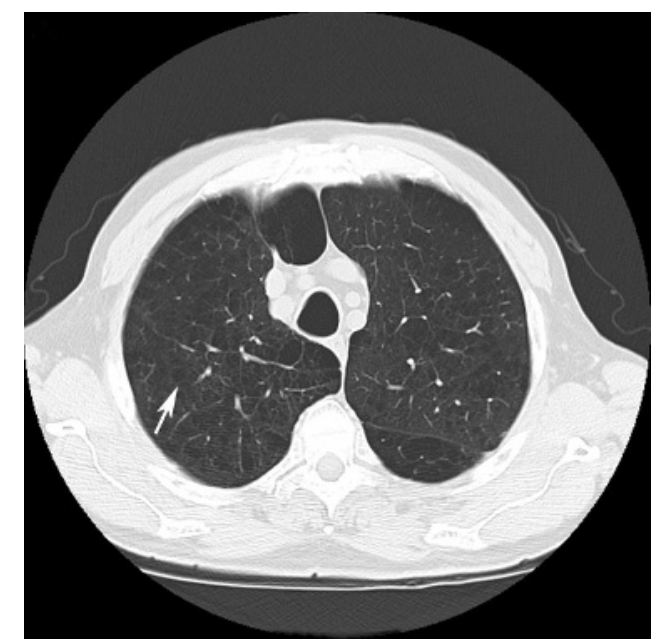

Figure 2 High-resolution CT scan showing emphysematous air space disease (arrow). In contrast to cystic lung disease, discrete walls are not present.

Chronic cavities, those present for $>1$ month, are more likely to be malignant, congenital or the result of chronic inflammatory disorders. ${ }^{7}$ Acute or subacute cavities, those present for $<1$ month and accompanied by the recent development of signs and symptoms, are often due to infections, inflammatory disorders ( such as Wegener's granulomatosis), thromboemboli/ septic emboli or trauma (fig 4). Infectious cavities may occur during or subsequent to a necrotising pneumonia (Staphylococcus aureus or Streptococcus pneumonia), post-primary tuberculosis (often with a posterior upper lobe preference) or chronic infection with opportunistic or endemic fungi (nocardiosis, sporotrichosis, aspergillosis, cryptococcosis, mucormycosis, histoplasmosis, blastomycosis or coccidioidomycosis). Pulmonary actinomycosis, which can mimic a bronchogenic carcinoma, may present as a persistent pulmonary mass or consolidation with cavitation. ${ }^{10}$ Atypical causes of cavities, which are not frequently seen outside endemic areas, include paragonimiasis, melioidosis and echinococcosis and should be considered depending on the clinical scenario.

\section{CYSTIC LUNG DISEASE}

Cystic lung disease may be subclassified into two types: (1) discrete, focal or multifocal cysts and (2) diffuse cysts with a pan-lobular distribution. Several congenital and acquired diseases may produce focal or multifocal cystic lung disease (table 2).

\section{Focal or multifocal cystic lung disease}

Congenital abnormalities

Bronchogenic cysts, pulmonary sequestration and congenital cystic adenomatoid malformations (CCAM) are congenital disorders that present clinically in early childhood or young 

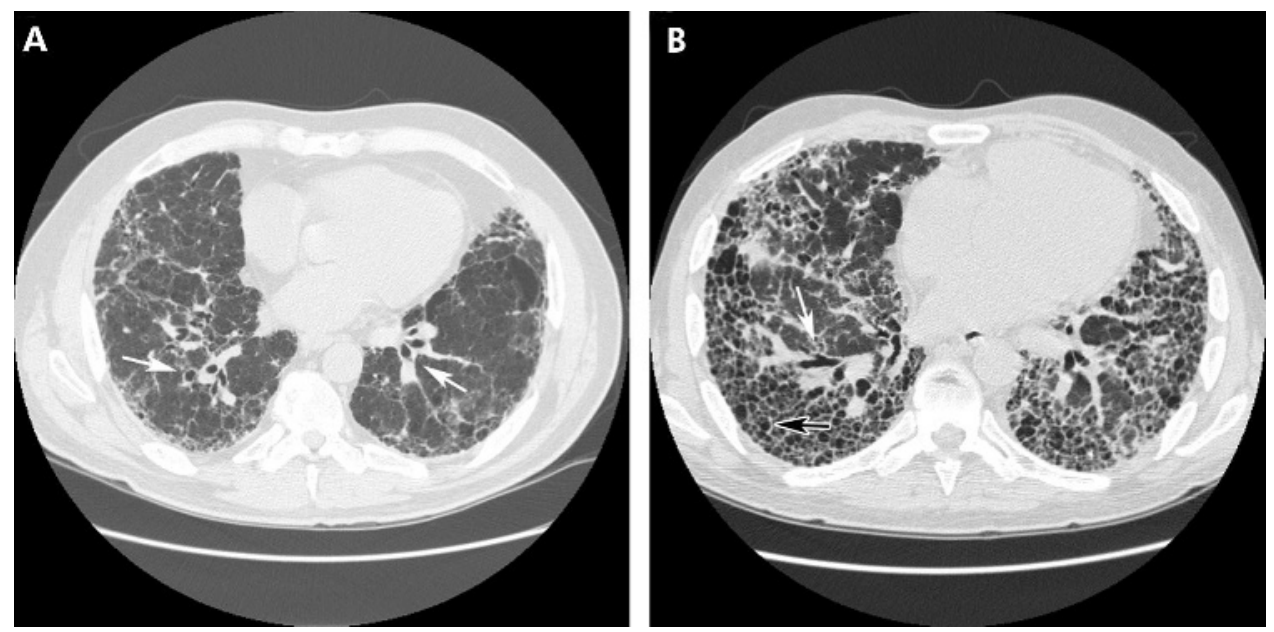

Figure 3 High-resolution CT scans from two patients with idiopathic pulmonary fibrosis showing traction bronchiectasis (white arrows). The adjacent bronchi and vasculature differentiates these structures from true cysts. End-stage lung fibrosis is evident with diffuse honeycombing (black arrow), reticulation and traction bronchiectasis.

adulthood. Bronchogenic cysts represent congenital abnormalities resulting from abnormal budding of the developing tracheobronchial tree. While they typically appear as either mediastinal or intraparenchymal homogeneous masses, they may also manifest as thin-walled cystic cavities with or without an air-fluid level, pneumothoraces or recurrent pneumonia. They do not communicate with the tracheobronchial tree unless they become secondarily infected, which occurs in $>75 \%$ of intraparenchymal cysts. Once infected and in communication with the tracheobronchial tree, the cysts often rapidly enlarge, some to $>25 \mathrm{~cm}$, due to a check valve mechanism. Haemoptysis often develops when this occurs. Mediastinal bronchogenic cysts may present with dyspnoea, stridor, cough or chest pain,

\begin{tabular}{l} 
Table 1 Aetiology of cavitary lung disease \\
\hline Neoplastic \\
Bronchogenic carcinomas \\
Metastatic carcinomas \\
Lymphoma \\
Infectious \\
Bacterial \\
Staphylococcus aureus pneumonia \\
Streptococcus pneumonaie pneumonia \\
Mycobacterial disease \\
Melliodosis \\
Actinomycosis \\
Pneumocystis carinii pneumonia \\
Norcardiosis \\
Fungi \\
Histoplasmosis \\
Coccidioidomycosis \\
Blastomycosis \\
Mucormycosis \\
Aspergilliosis \\
Cryptococcosis \\
Parasites \\
Hydatid disease \\
Echinococcus granulosus \\
Echinococcus multilocularis \\
Paragonimiasis \\
Amoebiasis \\
Immunological/autoimmune \\
Wegener's granulomatosis \\
Rheumatoid arthritis \\
Thromboembolic/septic embolism \\
Pneumoconiosis \\
Silicosis \\
Bronchiectasis \\
Congenital \\
Sequestration \\
Congenital adenomatoid malformation \\
\hline
\end{tabular}

depending upon the location, secondary to a mass effect and compression from the lesion.

Bronchopulmonary sequestration is one of the more common congenital pulmonary malformations. In sequestration, a portion of lung develops with its own systemic arterial blood supply isolated from the main body of the lung. Two variants exist: intralobar sequestration (encompassed by the same visceral pleural envelope as the adjacent surrounding lung) and extralobar sequestration (encompassed by a separate distinct visceral pleura); $75 \%$ of sequestrations are intralobar with two-thirds of them occurring in the posterior basilar segment of the left lower lobe and up to one-third in a similar location on the right. ${ }^{11}$ Upper lobe intralobar sequestration is rare but, if present, may be accompanied by other congenital malformations. Most sequestrations are diagnosed in childhood or in young adults presenting with a history of recurrent pneumonia. In the adult the age at the time of diagnosis ranges from 20 to 70 years. ${ }^{12}$ As in intralobar sequestration, extralobar sequestration occurs most often on the left and is often peripheral and presents as a wedge-shaped density associated with the left diaphragm in $90 \%$ of cases. While the majority of

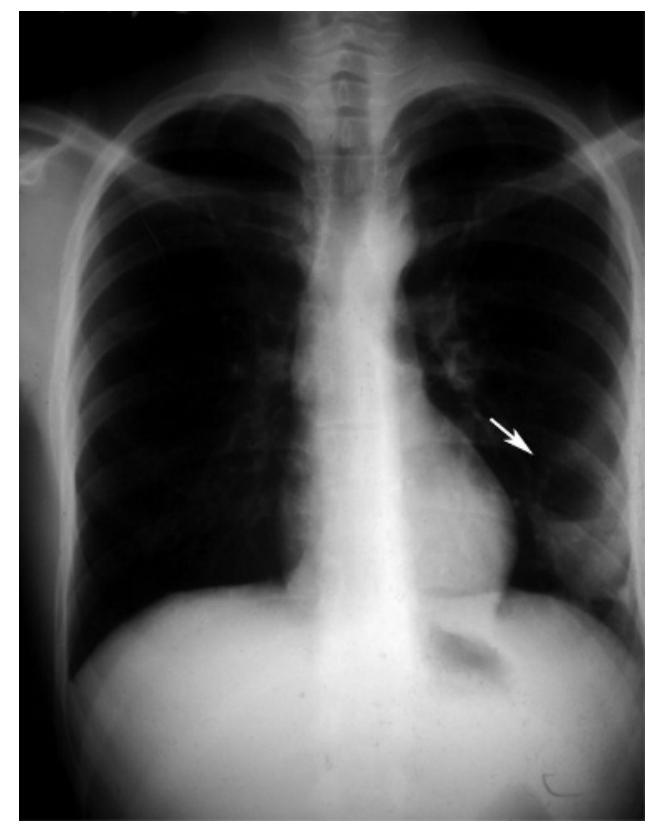

Figure 4 Posteroanterior radiograph showing a lung cyst in the left midlung zone following blunt chest trauma. 


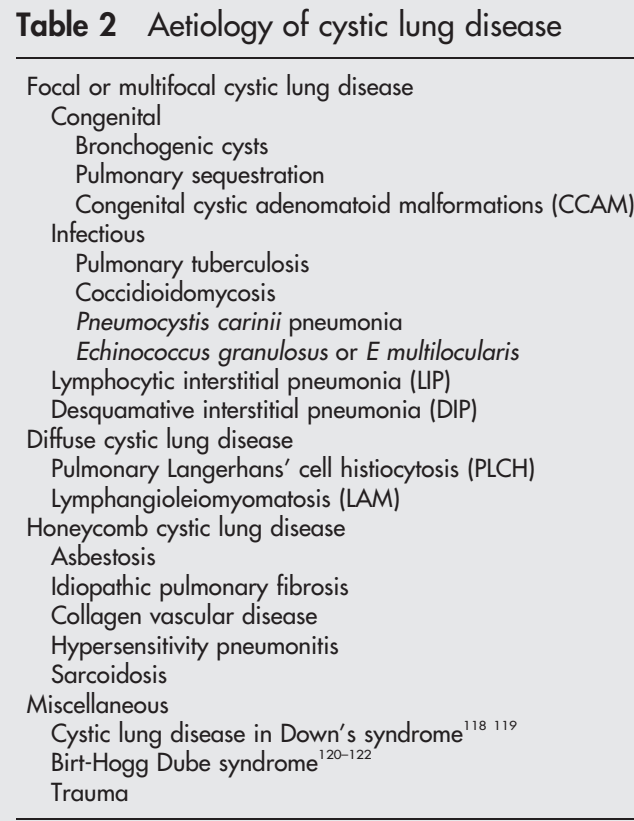

sequestrations present radiographically as homogeneous masses, cysts may also be seen (fig 5). A definitive diagnosis is made by demonstrating its systemic arterial blood supply.

CCAM refers to a group of pulmonary anomalies believed to represent localised arrested development of the fetal bronchial tree. Most cases are identified with prenatal ultrasonography. ${ }^{13}$ In those not identified antenatally, patients are usually diagnosed within 1 month of birth. Some individuals, however, have been diagnosed as late as 60 years of age. ${ }^{14}$ Three subtypes of CCAM exist: type I (cystic), type II (intermediate) and type III (solid). Type I cystic adenomatoid malformations are the most common and represent more than half of all CCAMs. ${ }^{14}$ In the newborn infant, cystic and intermediate CCAMs begin as homogenous masses that become air filled in the days to weeks following birth. CT scanning is superior to plain chest radiography and shows multiple thin-walled complex cystic masses ranging in size from 2 to $12 \mathrm{~cm}$. The cysts may contain air, fluid or both. CCAMs may occur in either the upper or lower lobes with up to $15 \%$ of cases being bilateral..$^{15-17}$ Most patients will present with neonatal respiratory distress. Pneumothorax or recurrent pneumonia are less common but represent the typical manifestation in adults. ${ }^{16}$ Bronchoalveolar carcinoma can complicate cystic CCAMs. ${ }^{18}$ In those that present after birth, CT imaging is the diagnostic entity of choice. Surgical resection, preferably a lobectomy, is curative. Recurrences have been described in patients in whom more selective resection was attempted, presumably due to residual anomalous tissue. ${ }^{19}$

\section{Infections}

Several infections may present with pneumatoceles, a specific subcategory of cystic airspace disease. Pneumatoceles are cysts that present acutely or subacutely and are progressive until the underlying infection is treated, after which they usually resolve. They occur most commonly with Staphylococcus aureus and Pneumocystis carinii pneumonias and are more common in children. True infectious cysts that persist despite resolution of the primary infection may occur with Pneumocystis carinii pneumonia or echinococcosis (hydatid disease). Hydatid cysts occur as a result of infection with Echinococcus granulosus or E multiloculus and are often multiple, occurring most commonly in the upper lobes. The cysts associated with Pneumocystis carinii pneumonia most often occur in patients with advanced HIV infection and AIDS, are multiple, usually apical in distribution, and range in size from 1 to $5 \mathrm{~cm}$ in diameter. Although isolated cysts may occur in coccidioido-mycosis, cavitary disease from a necrotising infection remains the more common manifestation of this infection.

\section{Lymphocytic interstitial pneumonia}

Lymphocytic interstitial pneumonitis (LIP) is a rare interstitial lung disease which was originally described by Carrington and Liebow in $1966 .{ }^{20}$ Both idiopathic and secondary forms are described, many of which are associated with some form of dysproteinaemia or autoimmunity. ${ }^{21-26} 50-77 \%$ of patients with LIP, including those with the idiopathic variety, have some associated serum protein abnormality, most often polyclonal gammopathy (IgG or IgM) $)^{27-33}$ but also hypogammaglobulinaemia. ${ }^{27}{ }^{34}$ Sjögren's syndrome accounts for at least $25 \%$ of reported cases. ${ }^{21} 293135-37$ Several cases of common variable hypogammaglobulinaemia have been complicated by LIP $^{29}$ with a high incidence of conversion to a lymphoreticular malignancy. ${ }^{38}$ Retroviral (HIV-1, HTLV-1) and Epstein-Barr viral infections have been identified in some patients with LIP, but their exact role remains unclear. ${ }^{21} 26$ 39-42

LIP occurs more commonly in women and presents between the fourth and seventh decades of life with a mean age at diagnosis of 56 years. ${ }^{29} 304344$ It may occur in children, particularly those with hypogammaglobulinaemia or AIDS, ${ }^{45-48}$ and a familial form of LIP has also been reported. ${ }^{49}{ }^{50}$ The most common presenting symptoms are progressive dyspnoea and cough. ${ }^{28} 29{ }^{36}$ Additional symptoms include weight loss, pleuritic pain, arthralgias and fever. Clubbing and bibasilar rales are common physical findings. It is distinguishable from other interstitial pneumonias by the presence of monotonous sheets of lymphocytes expanding the interstitium and compressing alveolar spaces. ${ }^{27}$ Alveolar collections of lymphocytes as well as perilymphatic and perivascular aggregates may also occur in LIP. ${ }^{51} 52$ This lymphocytic infiltrate is associated with type II cell hyperplasia; the accumulation of large interstitial reticuloendothelial cells, mononuclear cells and giant cells forming noncaseating granulomas; ${ }^{21}{ }^{53}$ perivascular and paraseptal amyloid deposition; 374445554 and well-formed lymphoid germinal centres. $^{20}$ The lymphocyte aggregates in LIP are polyclonal; the few reports of monoclonal lymphocyte populations raise the concern of a premalignant condition. ${ }^{55-57} \mathrm{~B}$ cells and $\mathrm{T}$ cells are both present, with B cells typically located in the lymphoid nodules whereas $\mathrm{T}$ cells are primarily located in the lung interstitium. ${ }^{27} 3544$

Radiographically, bibasilar reticulonodular infiltrates are common, with single or multiple well-circumscribed masses often coalescent with air bronchograms. However, prominent cysts occur in up to two-thirds of patients. ${ }^{58}$ The thin-walled cysts are multifocal and variable in size and shape. A series of CT scans of 14 patients with LIP followed over a median of 13 months reported ground glass attenuation, thickening of interlobular septae, focal consolidation, centrilobular nodules and cystic airspaces (fig 6). All the parenchymal abnormalities were reversible with treatment with the exception of the cysts, and new cysts developed in areas of prior centrilobular nodularity. ${ }^{59}$ Other CT features that have been reported include lymph node enlargement (in $68 \%$ of patients), subpleural small nodules (in 86\%) and thickening of bronchovascular bundles (in 86\%). ${ }^{60}$ Mixed alveolar-interstitial and a micronodular pattern, honeycombing as well as signs of pulmonary hypertension have been reported. ${ }^{30} 546162$ Rarely, recurrent pneumothoraces may be a presenting sign. ${ }^{63}$ Pleural effusions are rare, except in AIDS-related LIP, and should raise the concern for a lymphoproliferative disorder. ${ }^{62}$

The prognosis in LIP is variable with four potential outcomes: (1) resolution following corticosteroid therapy alone or in 

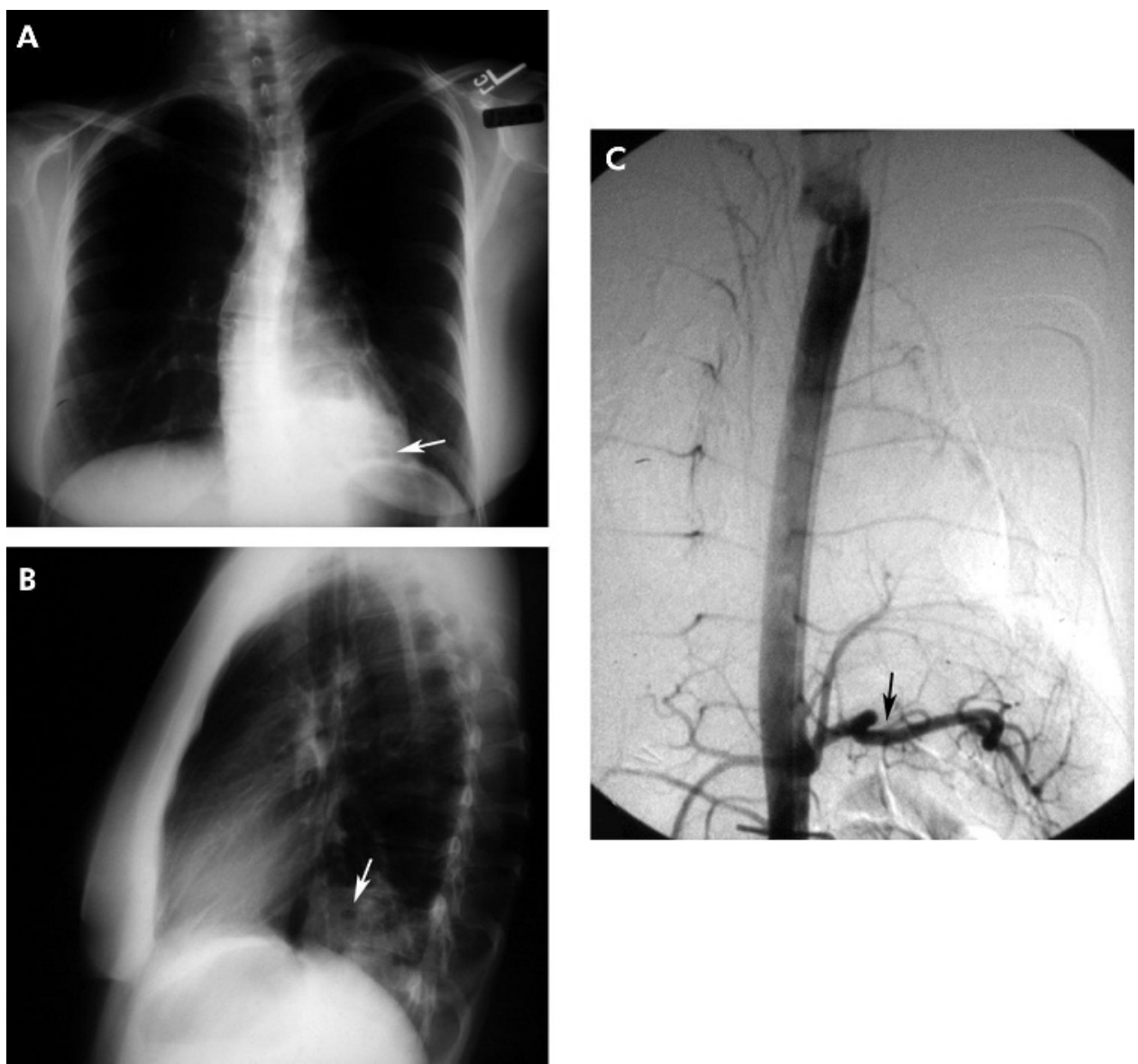

Figure 5 (A) Posteroanterior and (B) lateral radiographs showing cystic airspace abnormalities in the left lower lobe, posterior segment. An intralobar sequestration is confirmed by angiography which shows a systemic arterial supply arising from the aorta (C).

combination with other immunosuppressive drugs; ${ }^{30} 35$ (2) progressive pulmonary fibrosis; $;^{29}{ }^{30}$ (3) overwhelming pulmonary or systemic infection; $;^{29} 30$ and (4) conversion to lymphoma..$^{27} 305464$ Median survival is reported as 11.5 years. ${ }^{65}$ The data regarding response to treatment are uncontrolled, often unaccompanied by objective testing, with dosage schedules differing among reports. However, progressive disease despite aggressive treatment can occur. Unfortunately, there are no clinical, laboratory or histological parameters that help to predict an individual's outcome. Bacterial superinfection is a common cause of death, especially in those with hypogammaglobulinaemia. ${ }^{29} 3034$

\section{Desquamative interstitial pneumonia}

Desquamative interstitial pneumonitis (DIP) is a rare idiopathic interstitial pneumonia first described by Liebow. ${ }^{66}$ It is a disease that is seen almost exclusively in current or former smokers. Men appear to be affected twice as often as women and the mean age of onset is 42 years. ${ }^{67}$ Cough and dyspnoea are the most common symptoms, occurring subacutely over weeks to months. ${ }^{68}$ Pathologically it is characterised by the accumulation of pigmented macrophages within the airspaces with a homogenous appearance and limited mononuclear infiltrate within the interstitium. ${ }^{6769}$ This contrasts with the peribronchiolar accumulation of macrophages in respiratory
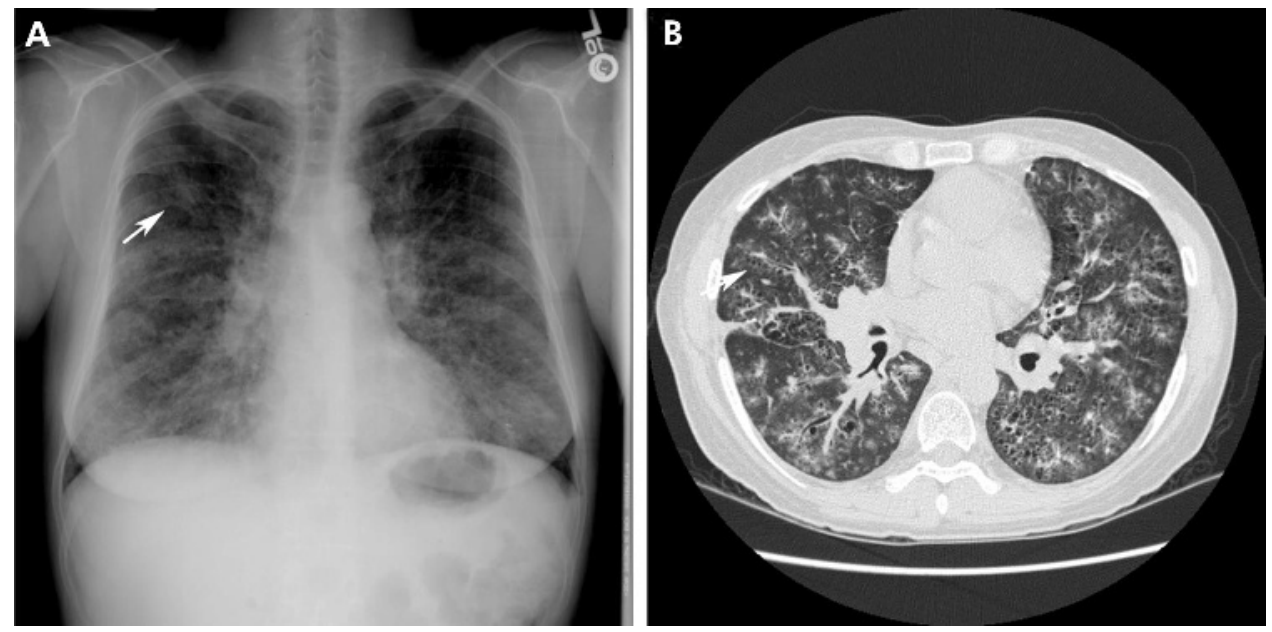

Figure 6 (A) Posteroanterior radiograph showing diffuse reticulonodular infiltrates with associated cysts (arrow) in lymphocytic interstitial pneumonia. The cysts are peribronchiolar in distribution (arrow) based on high-resolution CT scans (B). 

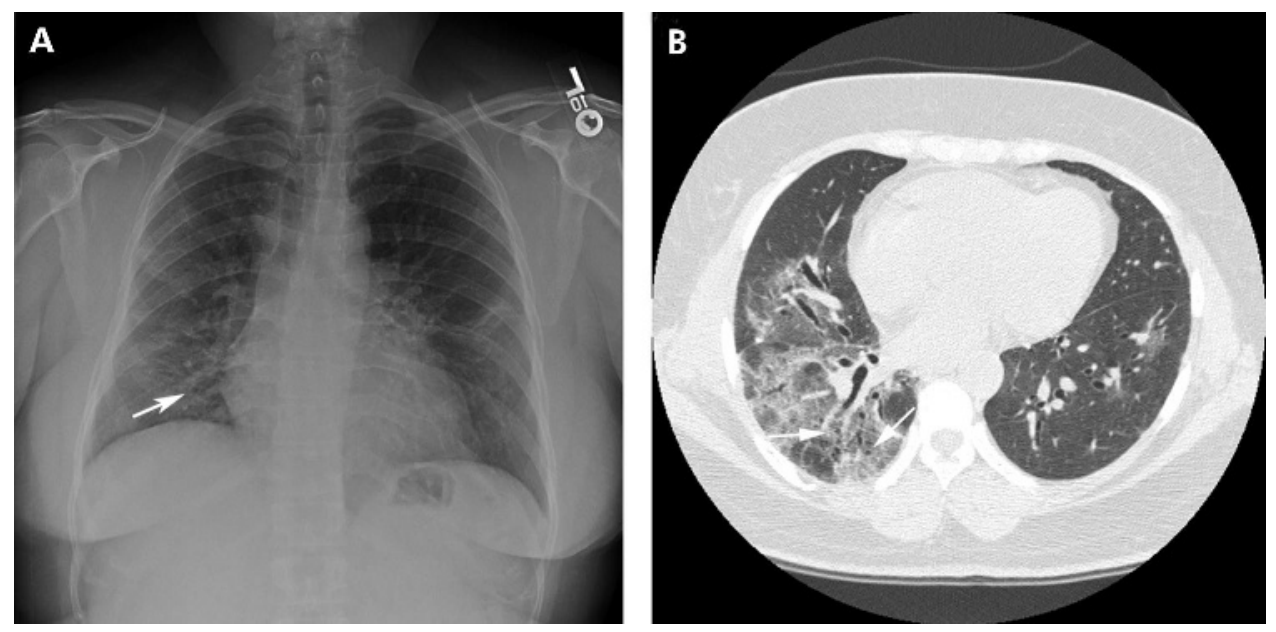

Figure 7 (A) Posteroanterior radiograph from a patient with desquamative interstitia pneumonitis showing diffuse ground glass opacities with cysts (arrow). (B) A highresolution $\mathrm{CT}$ scan from the same patient more clearly shows cysts within ground glass opacities. Traction bronchiectasis is also present, suggesting that the ground glass opacities are secondary to fibrosis rather than an inflammatory process.

bronchiolitis interstitial lung disease (RB-ILD). Its characteristic radiographic manifestations include diffuse ground glass opacities with parenchymal cysts (fig 7). In $25-44 \%$ of patients a diffuse ground glass pattern is seen in the middle to lower lung zones on plain chest radiographs and in all patients on HRCT imaging. ${ }^{71}$ Cysts were present in six of eight patients in one series and appeared to resolve following immunosuppressive therapy. ${ }^{68} 72$ In contrast to honeycomb cysts, which may also occur in DIP, isolated parenchymal cysts occur within areas of ground glass, remote from areas of end-stage fibrosis and honeycomb cystic disease. ${ }^{68}$

Treatment for DIP consists of tobacco cessation and corticosteroids. More than two-thirds of patients symptomatically and radiographically improve with corticosteroids. However, progressive deterioration despite treatment may occur in up to $30 \%$ of patients. ${ }^{73}$ Overall survival is significantly better than that experienced by patients with idiopathic pulmonary fibrosis (IPF), approaching $70-100 \%$ at 10 years. ${ }^{74} 7^{75}$

\section{Diffuse cystic lung disease}

Diffuse cystic lung disease is invariably one of two rare disorders: pulmonary Langerhans' cell histiocytosis (PLCH) or lymphangioleiomyomatosis (LAM).

\section{Pulmonary Langerhans' cell histiocytosis}

Pulmonary Langerhans' cell histiocytosis (PLCH) is a rare interstitial lung disease seen primarily in young adults. While the terms eosinophilic granulomatosis and pulmonary histiocytosis X have previously been used for this disorder, the currently preferred term is PLCH. It is part of a spectrum of systemic diseases termed Langerhans' cell histiocytosis. In these disorders the lung, bone, pituitary gland, thyroid, skin, lymph nodes and liver may be involved in isolation or combination. There is an established classification system to denote the various forms of isolated or multiorgan involvement. ${ }^{76}$ PLCH indicates clinically significant lung involvement with or without additional organ involvement.

PLCH affects individuals in their 20s and 30s and, similar to DIP, the vast majority are active tobacco smokers. ${ }^{78}{ }^{78}$ Patients typically present with non-productive cough and dyspnoea, occasionally accompanied by chest pain which is often pleuritic. ${ }^{79}$ Pneumothorax is the initial manifestation in $15 \%$ of patients and commonly recurs. ${ }^{80} 81$ Haemoptysis is less common, occurring in up to $5 \%$ of patients. Fever, anorexia and weight loss may occur in up to one-third of patients. Approximately $25 \%$ are asymptomatic at the time of presentation. $^{82}$

Langerhans' cell infiltration is the pathological hallmark. These cells are derived from monocyte-macrophage progenitors and function as antigen presenting cells. The presence of Birbeck granules or pentalaminar rod-shaped intracellular structures on electron microscopy and CDla immunoreactivity make these cells unique. ${ }^{83}$ Eosinophils, lymphocytes, fibroblasts and multinucleated giant cells accompany Langerhans' inflammation. The infiltration and subsequent Langerhans' cell monoclonal proliferation occurs in a bronchiolocentric
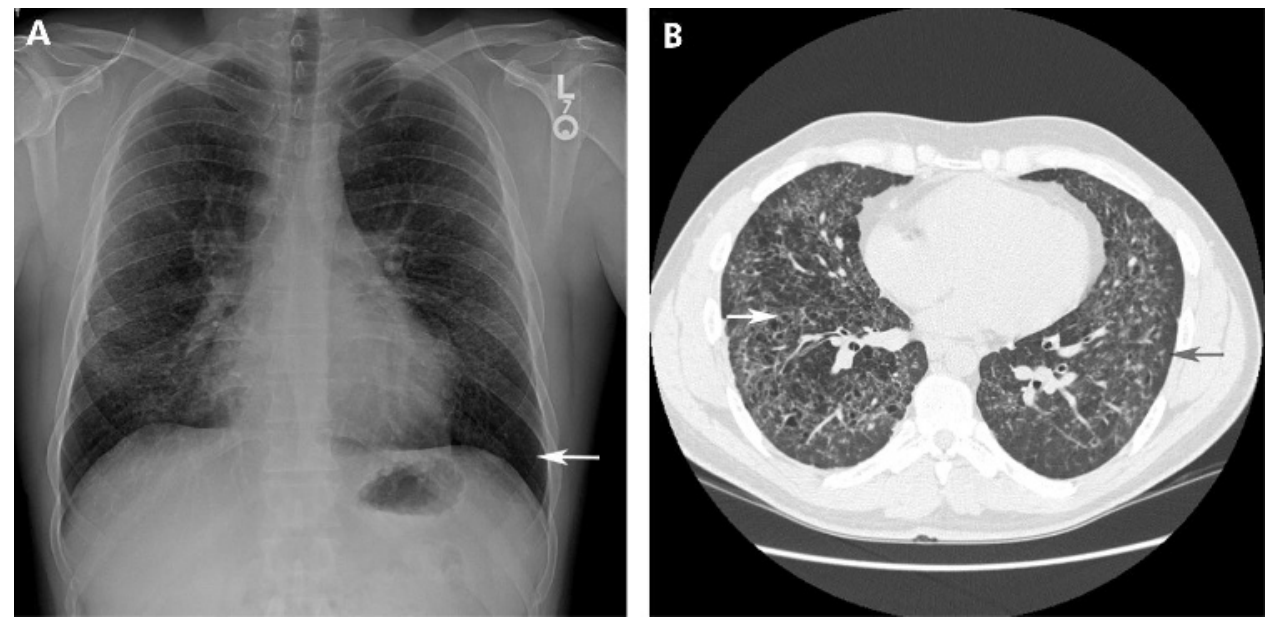

Figure 8 (A) Posteroanterior radiograph from a patient with pulmonary Langerhans' cell histiocytosis (PLCH). Diffuse reticulonodular infiltrates are present with sparing of the costophrenic sulci (arrow). (B) High-resolution CT scan showing diffuse irregularly shaped cysts (white arrow) with adjacent nodules (black arrow), features that characterise $\mathrm{PLCH}$. 
distribution with micronodule formation (1-5 mm). As the disease progresses, nodules evolve from a predominantly cellular lesion to a fibrotic one, with a characteristic stellate appearance. Destruction of the bronchiolar wall leads to bronchiolar dilation and cyst formation. Histopathologicalradiographic correlation suggests that the cellular bronchiolocentric nodules correspond to radiographic nodules whereas cavitary nodules and fibrous cysts correspond to cysts.

Radiographic studies reveal a characteristic combination of diffuse cysts and centrilobular micronodules (fig 8). ${ }^{84}$ In an active smoker the combination is virtually diagnostic. Early in the course of the disease nodules may dominate whereas, over time, diffuse cysts become more common. The abnormalities are diffuse and symmetrical with a characteristic sparing of the costophrenic sulci. The cysts in PLCH vary in size and shape, in contrast to the uniform appearance of cysts in lymphangioleiomyomatosis (LAM). ${ }^{85} 86$ Most cysts are $<10 \mathrm{~mm}$ in diameter but, with progression, confluence of adjacent cysts occurs, leading to irregular-shaped cystic airspaces, enlarging up to $80 \mathrm{~mm}$ in diameter. ${ }^{87}$ In contrast to most interstitial lung diseases, lung volumes may be preserved in $\mathrm{PLCH}{ }^{80}$ In one series of 81 patients pulmonary physiology was normal in $13.6 \%$ of patients. Obstructive $(27.2 \%)$, restrictive $(45.7 \%)$ or mixed defects $(4.9 \%)$ are commonly seen. ${ }^{88}$ Reduced carbon monoxide transfer factor is present in $60-90 \%$ of patients. ${ }^{77}$ Dilation of the main and central arteries may occur over time, suggesting the development of pulmonary hypertension ${ }^{89}$ which may be due to vascular involvement with intimal fibrosis, medial hypertrophy or luminal obliteration. ${ }^{90} 91$

PLCH may evolve in one of three ways: progression, stabilisation or resolution. Smoking cessation is the cornerstone of treatment, but this alone does not guarantee resolution or even stabilisation. However, most patients experience some degree of stabilisation in the short term. Corticosteroids may be beneficial, although there limited data are available to support their use. It is reasonable to consider a trial of corticosteroid treatment in patients who have progressive disease despite smoking cessation. In our experience, those patients with early primarily nodular infiltrates appear to have the most beneficial response to corticosteroids. In patients who develop pneumothoraces, early pleurodesis reduces the risk of recurrence and is not a contraindication for subsequent lung transplantation. ${ }^{81}$

The prognosis for most patients with PLCH is good with 5 year and 10 year survival rates of $74 \%$ and $64 \%$, respectively. ${ }^{88}$ The estimated mean survival from the time of diagnosis is 13 years. ${ }^{88}{ }^{92}$ In two retrospective studies, $27 \%$ of patients died or required transplantation for progressive disease. Recurrence within the donor lung has been reported by two separate groups. ${ }^{93} 94$

\section{Lymphangioleiomyomatosis}

Lymphangioleiomyomatosis (LAM) is a rare diffuse lung disease that is characterised by an abnormal proliferation of atypical smooth muscle cells within the lung, kidney, lymphatics or any combination. ${ }^{95}$ It may occur sporadically or in association with the neurocutaneous syndrome, tuberous sclerosis. Approximately 400 cases of LAM have been reported, most of which were sporadic. ${ }^{96}$ Recent studies suggest that up to one-third of women with tuberous sclerosis have a subclinical cystic lung disease consistent with LAM. ${ }^{96}$ The peak prevalence is in the third and fourth decade, primarily in women of child-bearing age but post-menopausal women have been diagnosed with LAM. ${ }^{97}{ }^{98}$ In contrast to PLCH, there is no association with smoking.

Patients with either sporadic or the tuberous sclerosisassociated form may present with pulmonary or extrapulmonary signs and symptoms. Progressive dyspnoea and pneumothorax are the two most common initial presentations in sporadic LAM. ${ }^{98} 99$ Dyspnoea may be due to either diffuse cystic lung disease or secondary to a chylous effusion, a manifestation of an obstructing lymphangiomyoma. ${ }^{100}$ Pulmonary function tests are abnormal in most patients, with a decreased carbon monoxide transfer factor occurring most frequently. ${ }^{99}$ Hypoxaemia, obstruction with an increased residual volume and mixed obstructive-restrictive defects may also be seen. Up to $26 \%$ of patients may have improved airflows after bronchodilator therapy. ${ }^{99}$ Extrapulmonary manifestations are common at presentation, particularly in the abdomen. The most common intra-abdominal findings include renal angiomyolipomas (AML), enlarged abdominal lymph nodes and lymphangiomyomas (cystic spaces filled with low attenuation fluid) in 10$20 \%$. Ascites, dilation of the thoracic duct and hepatic AML can also be seen. ${ }^{101}$ Flank pain, haematuria and, rarely, abdominal haemorrhage may occur secondary to an AML which occur in $30-50 \%$ of patients with sporadic LAM and $70 \%$ of patients with tuberous sclerosis-associated LAM and range in size from 0.5 to $20 \mathrm{~cm} .^{96} 102103$ Large screening programmes in patients with tuberous sclerosis have shown that patients may also present with an abnormal radiograph without significant pulmonary symptoms. ${ }^{104} 105$

Abnormal smooth muscle proliferation in LAM has been linked to the tuberous sclerosis complex (TSC) as mutations in TSC1 and TSC2, the genes encoding hamartin and tuberin, have been identified in patients with tuberous sclerosis-associated LAM and sporadic LAM. In tuberous sclerosis, germline mutations in TSC1 are heterozygous. LAM occurs in these patients following loss of heterozygosity of TSC1. In sporadic LAM, homozygous somatic mutations in TSC2 are present in the lung lesions and angiomyolipomas of patients. ${ }^{106}$ Following the loss of tuberin, a failure of signalling through the TSC pathway occurs, leading to dysregulated endocytosis, cellular proliferation, and loss of control of cell cycle with resulting abnormal smooth proliferation. ${ }^{107} 108$

Common to pulmonary and extrapulmonary LAM are foci of abnormal smooth muscle cells termed LAM nodules. Two distinct populations of cells exist: small spindle-shaped cells which are located at the centre of LAM lesions and large epithelioid cells abutting the periphery. Each cell has a different rate of proliferation and can be differentiated based on its immunoreactivity with HMB45, a pre-melansomal protein. Notably absent is a significant inflammatory response. Within the lung, LAM nodules are directly adjacent to areas of cystic change. Lining these cystic spaces, the aetiology of which is unclear, are hyperplastic type II cells, in contrast to the hyperplastic type I cells present in emphysema. ${ }^{109}$ Isolated type II cell hyperplasia may also occur in the absence of LAM nodules. In tuberous sclerosis, type II pneumocytes form clusters termed multifocal micronodular pneumocyte hyperplasia that are unique to TSC and may occur in the absence of LAM in these patients. These lesions are not associated with mutations in TSC2. ${ }^{110}$

Plain chest radiographic abnormalities in patients with LAM may be mild or absent at presentation, depending on the severity of the disease. The chest radiograph is non-specific, demonstrating normal to hyperinflated lung volumes with bilateral reticular opacities (fig 9). Small nodules may be present but, in contrast to PLCH, they are not as diffuse. Pneumothoraces, which are present in up to $50 \%$ of patients at presentation, occur in up to $80 \%$ of patients during the course of their disease. ${ }^{111}$ Pleural effusions, typically chylous, occur in up to $20 \%$ of patients. With advanced disease, diffuse cysts and bullae may occur. HRCT imaging in the appropriate clinical setting is diagnostic. ${ }^{112}$ It shows thin-walled cysts of variable size diffusely distributed throughout all lung fields (fig 9). The cysts may vary in size from 2 to $40 \mathrm{~mm}$. Vessels can be 

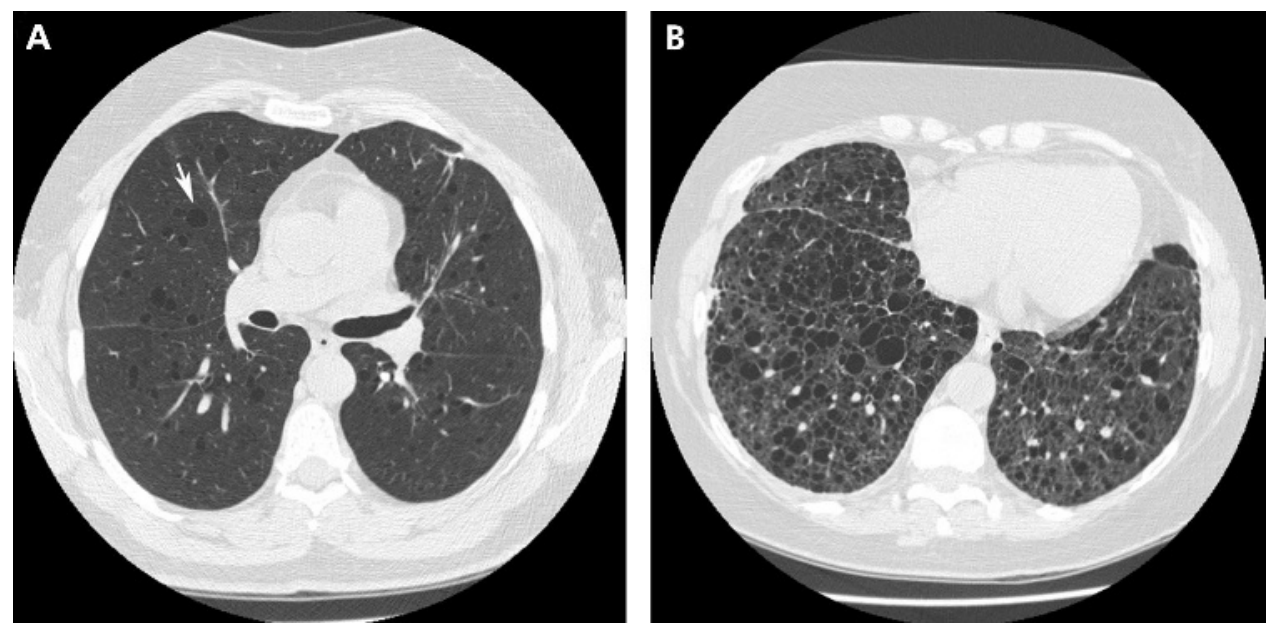

Figure 9 High-resolution CT scans from two patients with lymphangioleiomyomatosis (LAM). Diffuse, discrete, uniform cysts (arrow) are present early in the course of the disease (A). As the disease progresses, cysts may coalesce to form larger cysts (B). In contrast to pulmonary Langerhans' cell histiocytosis, nodules are not a prominent feature in LAM.

identified at the periphery of the cysts, in contrast to emphysema in which vessels are present within the centre of the lesion. ${ }^{113}$ The cyst walls are $1-2 \mathrm{~mm}$ in thickness and, in the absence of high-resolution imaging, patients may be misdiagnosed as having emphysema. Septal thickening occurs but is atypical and may represent lymphatic dilation due to smooth muscle proliferation and obstruction.

The natural history of LAM is variable and therapeutic options for its treatment are controversial. No medical treatment has been proved to be beneficial. In those with severe progressive disease, lung transplantation remains the cornerstone of treatment. While some patients may respond to hormone manipulation, most appear resistant to this approach. ${ }^{114-116}$ We do not generally recommend hormonal manipulation in our patients, but do treat reversible airflow limitation with inhaled $\beta$ agonists and recommend pleurodesis in those with recurrent pneumothoraces. Animal studies suggest that rapamycin, a peptide isolated from Streptomyces hygroscopicus with potent immunosuppressive properties, may have some role in treatment in the future. An early phase trial investigating the efficacy of rapamycin in the treatment of AMLs in tuberous sclerosis and LAM is in progress. ${ }^{17}$

\section{CONCLUSIONS}

While two diffuse (PLCH and LAM) and two focal or multifocal (DIP and LIP) cystic lung diseases are the most commonly considered problems, cystic lung disease may be caused by a variety of congenital and acquired lung diseases. As the prognosis-and therefore evaluation and subsequent management-may fundamentally differ among them, a confident diagnosis is important. Separation of cystic disease from its mimics such as cavities, emphysema and honeycombing is necessary in this regard. The clinical and, more important, the HRCT features of wall thickness, size, overall number and anatomical distribution can provide a high degree of confidence in a particular diagnosis or limit the differential diagnosis to only a few possibilities.

\section{Authors' affiliations}

G P Cosgrove, S K Frankel, K K Brown, Department of Medicine, National Jewish Medical and Research Center and Division of Pulmonary Sciences and Critical Care Medicine, University of Colorado Health Sciences Center, Denver, Colorado, USA

This work is supported by the NIH (NHLBI SCOR HL67671).

Competing interests: None.

Dr Cosgrove is a Parker B Francis Fellow in Pulmonary Research.

\section{REFERENCES}

1 Tuddenham WJ. Glossary of terms for thoracic radiology:recommendations of the Nomenclature Committee of the Fleischner Society. AJR Am J Roentgenol 1984; 143:509-17

2 Mitlehner W, Friedrich M, Dissmann W. Value of computer tomography in the detection of bullae and blebs in patients with primary spontaneous pneumothorax. Respiration 1992;59:221-7.

3 Laws J, Heard B. Emphysema and the chest film: a retrospective radiological. $\mathrm{Br} J$ adiolR 1962;35:750-61.

4 Simon G. Radiology and emphysema. Clin Radiol 1964;15:293-306.

5 Lynch DA. Imaging of diffuse parenchymal lung disease. In: Schwarz MI, King $\mathrm{TE}$, eds. Interstitial lung disease. Hamilton, Ontario: B C Decker, 2003:75-113.

6 Meziane MA, Hruban RH, Zerhouni EA, et al. High resolution CT of the lung parenchyma with pathologic correlation. Radiographics 1988;8:27-54.

7 Ryu JH, Swensen SJ. Cystic and cavitary lung diseases:focal and diffuse. Mayo Clin Proc 2003;78:744-52.

8 Woodring JH, Fried AM, Chuang VP. Solitary cavities of the lung: diagnostic implications of cavity wall thickness. AJR Am J Roentgenol 1980;135:1269-71.

9 Ryu J, Habermann T. Pulmonary lymphoma: primary and sytemic disease. Semin Respir Crit Care Med 1997; 18:341-52.

10 Smego RA Jr, Foglia G. Actinomycosis. Clin Infect Dis. 1998;26: 1255-61; quiz 1262-3).

11 Savic B, Birtel FJ, Tholen W, et al. Lung sequestration: report of seven cases and review of 540 published cases. Thorax 1979;34:96-101.

12 Ikezoe J, Murayama S, Godwin JD, et al. Bronchopulmonary sequestration: CT assessment. Radiology 1990;176:375-9.

13 Lujan M, Bosque M, Mirapeix RM, et al. Late-onset congenital cystic adenomatoid malformation of the lung. Embryology, clinical symptomatology, diagnostic procedures, therapeutic approach and clinical follow-up. Respiration 2002;69: 148-54.

14 Stocker JT, Madewell JE, Drake RM. Congenital cystic adenomatoid malformation of the lung. Classification and morphologic spectrum. Hum Pathol 1977;8:155-71.

15 Miller RK, Sieber WK, Yunis EJ. Congential adenomatoid malformation of the lung: a report of 17 cases, and review of the literature. In: Sommers SC, Rosen PP, eds. Pathology annual, part I. New York: Appleton-Century-Crofts, 1980:387

16 Patz EF Jr, Muller NL, Swensen SJ, et al. Congenital cystic adenomatoid malformation in adults: CT findings. J Comput Assist Tomogr 1995; 19:361-4.

17 Kim WS, Lee KS, Kim IO, et al. Congenital cystic adenomatoid malformation of the lung: CT-pathologic correlation. AJR Am J Roentgenol 1997;168:47-53.

18 Sheffield EA, Addis BJ, Corrin B, et al. Epithelial hyperplasia and malignant change in congenital lung cysts. J Clin Pathol 1987;40:612-4.

19 Sapin E, Lejeune VV, Barbet JP, et al. Congenital adenomatoid disease of the lung: prenatal diagnosis and perinatal management. Pediatr Surg Int 1997;12:126-9.

20 Carrington B, Liebow A. Lymphocytic interstitial pneumonia [abstract]. Am J Pathol 1966;48:36a.

21 Travis W, Fox C, Devany K, et al. Lymphoid pneumonitis in 30 adult patients infected with the human immunodeficiency virus: lymphocytic interstitial pneumonitis versus non-specific interstitial pneumonitis. Hum Pathol 1992;23:529-41.

22 Anon. Case records of the Massachusetts General Hospital (case 9-1986). N Engl J Med 1986;314:629-40.

23 Zucker L, Ongseng F, Goldfarb C. Lymphocytic interstitial pneumonitis:a cause of pulmonary gallium-67 uptake in a child with acquired immunodeficiency syndrome. J Nucl Med 1988;29:707-11.

24 Solal-Celigny P, Couderc L, Herman D, et al. Lymphoid interstitial pneumonitis in acquired immunodeficiency syndrome-related complex. Am Rev Respir Dis $1985 ; 131: 956-60$. 
25 Oldham S, Costillo M, Jacobsen F, et al. HIV associated lymphocytic interstitial pneumonia: radiologic manifestations and pathologic correlation. Radiology 1989;170:883-7.

26 Morris J, Rosen M, Marchevsky A, et al. Lymphocytic interstitial pneumonitis in patients at risk for the acquired immunodeficiency syndrome. Chest 1987:91:63-7.

27 Koss M, Hochholzer L, Langloss J, et al. Lymphoid interstitial pneumonia: clinicopathological and immunopathologic findings in 18 cases. Pathology 1987:19:178-85.

28 Salzstein S. Pulmonary malignant lymphomas and pseudolymphomas:classification, therapy and prognosis. Cancer 1963;16:928-55.

29 Bahadori M, Liebow A. Plasma cell granulomas of the lung. Cancer 1973;31:191-208.

30 Strimlan C, Rosenow El, Weiland L, et al. Lymphocytic interstitial pneumonitis: a review of 13 cases. Ann Intern Med 1978;68:616-21.

31 Alkhayer M, McCann B, Harrison B. Lymphocytic interstitial pneumonitis in association with Sjögren's syndrome. Br J Dis Chest 1988;82:305-9.

32 Moran T, Totten R. Lymphoid interstitial pneumonia with dysproteinemia: report of two cases with plasma cell predominance. Am J Clin Pathol 1970;54:747-56.

33 Young R, Tillman R, Burton A, et al. Lymphoid interstitial pneumonia with polyclonal gammopathy. J Natl Med Assoc 1969;61:310-4

34 Church J, Hart I, Saxon A, et al. Lymphoid interstitial pneumonitis and hypogammaglobulinemia in children. Am Rev Respir Dis 1981;124:491-6.

35 Kaufman S, Long J. Parotid mass and pulmonary nodules in a 36 year old woman. N Engl J Med 1977;297:652-60.

36 Baneriee D, Ahmad D. Malignant lymphoma complicating lymphocytic interstitial pneumonia:a monoclonal B-cell neoplasm arising in a polyclonal lymphoproliferative disorder. Hum Pathol 1982;13:780-2.

37 Strimlan C, Rosenow El, Divertie M, et al. Pulmonary manifestations of Sjögren's syndrome. Chest 1976;70:354-61.

38 Grieco M, Chinoy-Acharya P. Lymphocytic interstitial pneumonia associated with the acquired immunodeficiency syndrome. Am Rev Respir Dis 1985;31:952-5

39 Setoguchi Y, Takahashi S, Nukiwa T, et al. Detection of human T-cell lymphocytic virus type-I related antibodies in patients with lymphocytic interstitial pneumonitis. Am Rev Respir Dis 1991;144:1361-5.

40 Malamou-Mitsi V, Tsai M, Greer J, et al. Lymphoid interstitial pneumonitis not associated with HIV infection: role of Epstein-Barr virus. Mod Pathol 1992;5:487-91

41 Kramer M, Saldana M, Ramos M, et al. High titers of Epstein-Barr virus antibodies in adult patients with lymphocytic interstitial pneumonitis associated with AIDS. Respir Med 1992;86:49-52.

42 Barbera J, Hiayashi S, Hegele R, et al. Detection of Epstein-Barr virus in lymphocytic interstitial pneumonia by in situ hybridization. Am Rev Respir Dis 1992;145:940-6.

43 Halprin G, Ramirez R, Pratt P. Lymphoid interstitial pneumonia. Chest 1972;62:418-23.

44 Kohler P, Cook R, Brown W, et al. Common variable hypogammaglobulinemia with $T$ cell nodular interstitial pneumonitis and $B$ cell nodular hyperplasia: different lymphocyte populations with a similar response to prednisone therapy. $J$ Allergy Clin Immunol 1982;20:299-305.

45 Bonner HJ, Ennis R, Greelhoed G, et al. Lymphoid infiltration and amyloidosis of lung in Siögren's syndrome. Arch Pathol 1973:95:42-4.

46 Joshi V, Oleske J, Minnelor A, et al. Pathologic pulmonary findings in children with the acquired immunodeficiency syndrome: a study of ten cases. Hum Pathol 1985; 16:241-6.

47 Scott G, Buck B, Leterman J, et al. Acquired immunodeficiency syndrome in infants. N Engl'J Med 1984;310:76-81.

48 Goldman H, Ziprkowski M, Charytan M, et al. Lymphocytic interstitial pneumonitis in children with AIDS: a perfect radiographic-pathologic correlation. AJR 1985; 145:868A

49 O'Brodovich H, Moser M, Lu I, et al. Familial lymphoid pneumonia: a long term follow-up. Pediatrics 1980:63:523-8.

50 Wrighth J, Pennington P. Familial lymphoid interstitial pneumonitis [letter]. J Pediatr 1987; $111: 638$

51 Colby T, Yousem S. Pulmonary lymphoid lesions. Semin Diagn Pathol 1985;2:183-96.

52 Colby T. Lymphoproliferative diseases. In: Dail D, Hammar S, eds. Pulmonary pathology. New York: Springer-Verlag, 1988:711-26.

53 Liebow A, Carrington C. Diffuse pulmonary lymphoreticular infiltrations associated with dysproteinemia. Med Clin North Am 1973;57:809-43.

54 MacFarland A, Davies D. Diffuse lymphoid interstitial pneumonia. Thorax 1973;28:768-76.

55 Koss MN. Pulmonary lymphoid disorders. Semin Diagn Pathol 1995; 12:158-71.

56 Kurosu K, Yumoto N, Rom WN, et al. Aberrant expression of immunoglobulin heavy chain genes in Epstein-Barr virus-negative, human immunodeficiency virus-related lymphoid interstitial pneumonia. Lab Invest 2000;80:1891-903.

57 Kurosu K, Yumoto N, Furukawa M, et al. Third complementarity-determiningregion sequence analysis of lymphocytic interstitial pneumonia: most cases demonstrate a minor monoclonal population hidden among normal lymphocyte clones. Am J Respir Crit Care Med 1997;155:1453-60.

58 Johkoh T, Muller NL, Pickford HA, et al. Lymphocytic interstitial pneumonia: thin-section CT findings in 22 patients. Radiology 1999;212:567-72.

59 Johkoh T, Ichikado K, Akira M, et al. Lymphocytic interstitial pneumonia: followup CT findings in 14 patients. J Thorac Imaging 2000;15:162-7.
60 Heyneman LE, Ward S, Lynch DA, et al. Respiratory bronchiolitis, respiratory bronchiolitis-associated interstitial lung disease, and desquamative interstitial pneumonia: different entities or part of the spectrum of the same disease process? AJR Am J Roentgenol 1999;173:1617-22.

61 Ettensohn D, Mayer K, Kaassismian N, et al. Lymphocytic bronchiolitis associated with HIV infection. Chest 1988;93:201-2.

62 Buchwald I. Pulmonary pseudolymphoma presenting as a solitary nodular density with an air bronchogram. Chest 1974:65:691-3.

63 Parker J, Shellito V, Pei L, et al. Lymphocytic interstitial pneumonitis presenting as recurrent pneumothoraces. Chest 1991;100:1733-5.

64 DeCoteau W, Tourville D, Ambrus J, et al. Lymphoid interstitial pneumonia and autoerythrocyte sensitization syndrome. Arch Intern Med 1974;134:519-22.

65 Fessler M, Schwarz M, King TJ, et al. Lymphocytic interstitial pneumonitis vs. IPF: comparison of outcome, clinical, and physiologic variables, Am J Respir Crit Care Med 2001;63:706A

66 Liebow AA, Steer A, Billingsley JG. Desquamative interstitial pneumonia Am J Med 1965;39:369-404.

67 Katzenstein AL, Myers JL. Idiopathic pulmonary fibrosis: clinical relevance of pathologic classification. Am J Respir Crit Care Med 1998;157/4 Pt 1):1301-15.

68 Akira M, Yamamoto S, Hara H, et al. Serial computed tomographic evaluation in desquamative interstitial pneumonia. Thorax 1997:52:333-7.

69 American Thoracic Society/European Respiratory Society. International multidisciplinary consensus classification of the idiopathic interstitial pneumonias. Am J Respir Crit Care Med 2002;165:277-304.

70 American Thoracic Society. Idiopathic pulmonary fibrosis: diagnosis and treatment. International consensus statement. American Thoracic Society (ATS), and the European Respiratory Society (ERS). Am J Respir Crit Care Med 2000;161(2 Pt 1):646-64

71 Hartman TE, Primack SL, Swensen SJ, et al. Desquamative interstitial pneumonia: thin-section CT findings in 22 patients. Radiology 1993;187:787-90.

$72 \mathrm{Kim}$ KS, Kim YC, Park KO, et al. A case of completely resolved pneumatocoeles in desquamative interstitial pneumonia. Respirology 2003;8:389-95.

73 Yousem SA, Colby TV, Gaensler EA. Respiratory bronchiolitis-associated interstitial lung disease and its relationship to desquamative interstitial pneumonia. Mayo Clin Proc 1989;64:1373-80.

74 Carrington CB, Gaensler EA, Coutu RE, et al. Natural history and treated course of usual and desquamative interstitial pneumonia. N Engl J Med 1978;298:801-9.

75 Matsui K, Takeda K, Yu ZX, et al. Downregulation of estrogen and progesterone receptors in the abnormal smooth muscle cells in pulmonary lymphangioleiomyomatosis following therapy. An immunohistochemical study. Am J Respir Crit Care Med 2000;161(3 Pt 1):1002-9.

76 Favara BE, Feller AC, Pauli M, et al. Contemporary classification of histiocytic disorders. The WHO Committee On Histiocytic/Reticulum Cell Proliferations. Reclassification Working Group of the Histiocyte Society. Med Pediatr Oncol 1997;29:157-66.

77 Vassallo R, Ryu JH, Colby TV, et al. Pulmonary Langerhans'-cell histiocytosis. N Engl J Med 2000;342:1969-78.

78 Basset F, Corrin B, Spencer H, et al. Pulmonary histiocytosis X. Am Rev Respir Dis 1978;118:811-20.

79 Schonfeld N, Frank W, Wenig S, et al. Clinical and radiologic features, lung function and therapeutic results in pulmonary histiocytosis $X$. Respiration 1993:60:38-44

80 Lacronique J, Roth C, Battesti JP, et al. Chest radiological features of pulmonary histiocytosis X: a report based on 50 adult cases. Thorax 1982;37:104-9.

81 Mendez JL, Nadrous HF, Vassallo R, et al. Pneumothorax in pulmonary Langerhans cell histiocytosis. Chest 2004;125:1028-32.

82 Friedman PJ, Liebow AA, Sokoloff J. Eosinophilic granuloma of lung. Clinical aspects of primary histiocytosis in the adult. Medicine (Baltimore) 1981;60:385-96

83 Tazi A, Bonay M, Grandsaigne M, et al. Surface phenotype of Langerhans cells and lymphocytes in granulomatous lesions from patients with pulmonary histiocytosis X. Am Rev Respir Dis 1993;147(6 Pt 1):1531-6.

84 Fraser RG, Muller NL, Colman RL, et al, eds. Langerhans'cell histiocytosis. In: Diagnosis of the diseases of the chest, Philadelphia:W B Saunders, 1999: 1627-40

85 Moore AD, Godwin JD, Muller NL, et al. Pulmonary histiocyłosis X: comparison of radiographic and CT findings. Radiology 1989;172:249-54.

86 Bonelli FS, Hartman TE, Swensen SJ, et al. Accuracy of high-resolution CT in diagnosing lung diseases. AJR Am J Roentgenol 1998;170:1507-12.

87 Brauner MW, Grenier P, Mouelhi MM, et al. Pulmonary histiocytosis X: evaluation with high-resolution CT. Radiology 1989;172:255-8.

88 Vassallo R, Ryu JH, Schroeder DR, et al. Clinical outcomes of pulmonary Langerhans'-cell histiocytosis in adults. N Engl J Med 2002;346:484-90

89 Crausman RS, Lynch DA, Mortenson RL, et al. Quantitative CT predicts the severity of physiologic dysfunction in patients with lymphangioleiomyomatosis. Chest 1996;109:131-7.

90 Fartoukh M, Humbert M, Capron F, et al. Severe pulmonary hypertension in histiocytosis X. Am J Respir Crit Care Med 2000;161:216-23.

91 Travis WD, Borok Z, Roum JH, et al. Pulmonary Langerhans cell granulomatosis (histiocytosis X). A clinicopathologic study of 48 cases. Am J Surg Pathol 1993; 17:971-86.

92 Delobbe A, Durieu J, Duhamel A, et al. Determinants of survival in pulmonary Langerhans' cell granulomatosis (histiocytosis X). Groupe d'Etude en Pathologie Interstitielle de la Societe de Pathologie Thoracique du Nord. Eur Respir J 1996;9:2002-6. 
93 Gabbay E, Dark JH, Ashcroft T, et al. Recurrence of Langerhans' cell granulomatosis following lung transplantation. Thorax 1998;53:326-7.

94 Habib SB, Congleton J, Carr D, et al. Recurrence of recipient Langerhans' cell histiocytosis following bilateral lung transplantation. Thorax 1998;53:323-5.

95 Sullivan EJ. Lymphangioleiomyomatosis: a review. Chest 1998;114:1689-703.

96 Kristof AS, Moss J. Lymphangioleiomyomatosis. In: Schwarz MI, King TE, eds. Interstitial lung disease. Hamilton, Ontario: B C Decker, 2003:851-64.

97 Aubry MC, Myers JL, Ryu JH, et al. Pulmonary lymphangioleiomyomatosis in a man. Am J Respir Crit Care Med 2000;162(2 Pt 1):749-52.

98 Taylor JR, Ryu J, Colby TV, et al. Lymphangioleiomyomatosis. Clinical course in 32 patients. N Engl J Med 1990;323:1254-60.

99 Chu SC, Horiba K, Usuki J, et al. Comprehensive evaluation of 35 patients with lymphangioleiomyomatosis. Chest 1999;115:1041-52.

100 Pallisa E, Sanz P, Roman A, et al. Lymphangioleiomyomatosis:pulmonary and abdominal findings with pathologic correlation. Radiographics 2002;22(Special No):S185-98.

101 Avila NA, Kelly JA, Chu SC, et al. Lymphangioleiomyomatosis: abdominopelvic CT and US findings. Radiology 2000;216:147-153.

102 Matsui K, Tatsuguchi A, Valencia J, et al. Extrapulmonary lymphangioleiomyomatosis (LAM): clinicopathologic features in 22 cases. Hum Pathol 2000;31:1242-8.

103 Neumann HP, Schwarzkopf G, Henske EP. Renal angiomyolipomas, cysts, and cancer in tuberous sclerosis complex. Semin Pediatr Neurol 1998;5:269-75.

104 Moss J, Avila NA, Barnes PM, et al. Prevalence and clinical characteristics of lymphangioleiomyomatosis (LAM) in patients with tuberous sclerosis complex. Am J Respir Crit Care Med 2001;164:669-71.

105 Costello LC, Hartman TE, Ryu JH. High frequency of pulmonary lymphangioleiomyomatosis in women with tuberous sclerosis complex. Mayo Clin Proc 2000;75:591-4.

106 Carsillo T, Astrinidis A, Henske EP. Mutations in the tuberous sclerosis complex gene TSC2 are a cause of sporadic pulmonary lymphangioleiomyomatosis. Proc Natl Acad Sci USA 2000;97:6085-90.

107 Aicher LD, Campbell JS, Yeung RS. Tuberin phosphorylation regulates its interaction with hamartin. Two proteins involved in tuberous sclerosis. J Biol Chem 2001;276:21017-21.

108 Nellist M, van Slegtenhorst MA, Goedbloed M, et al. Characterization of the cytosolic tuberin-hamartin complex. Tuberin is a cytosolic chaperone for hamartin. J Biol Chem 1999;274:35647-52.
109 Ferrans VJ, Yu ZX, Nelson WK, et al. Lymphangioleiomyomatosis (LAM): a review of clinical and morphological features. J Nippon Med Sch 2000;67:311-29.

110 Maruyama H, Seyama K, Sobajima J, et al. Multifocal micronodular pneumocyte hyperplasia and lymphangioleiomyomatosis in tuberous sclerosis with a TSC2 gene. Mod Pathol 2001;14:609-14.

111 Kalassian KG, Doyle R, Kao P, et al. Lymphangioleiomyomatosis:new insights. Am J Respir Crit Care Med 1997;155:1183-6.

112 Aberle DR, Hansell DM, Brown K, et al. Lymphangiomyomatosis: CT, chest radiographic, and functional correlations. Radiology 1990;176:381-7.

113 Lynch DA, Brown KK, Lee J-S, et al. Imaging of diffuse infiltrative lung disease In: Lynch DA, Newell JD, Lee J-S, eds. Imaging of diffuse lung disease. Hamilton, Ontario and Lewiston, NY: B C Decker, 2000:57-140.

114 Taveira-DaSilva AM, Stylianou MP, Hedin CJ, et al. Decline in lung function in patients with lymphangioleiomyomatosis treated with or without progesterone. Chest 2004;126:1867-74.

115 Urban T, Lazor R, Lacronique J, et al. Pulmonary lymphangioleiomyomatosis. A study of 69 patients. Groupe d'Etudes et de Recherche sur les Maladies "Orphelines" Pulmonaires (GERM"O"P). Medicine (Baltimore) 1999;78:321-37

116 Johnson SR, Tattersfield AE. Decline in lung function in lymphangioleiomyomatosis: relation to menopause and progesterone treatment. Am J Respir Crit Care Med 1999;160:628-33.

117 Kenerson HL, Aicher LD, True LD, et al. Activated mammalian target of rapamycin pathway in the pathogenesis of tuberous sclerosis complex renal tumors. Cancer Res 2002;62:5645-50.

118 Tyrrell VJ, Asher MI, Chan Y. Subpleural lung cysts in Down's syndrome. Pediatr Pulmonol 1999;28:145-8.

119 Joshi VV, Kasznica J, Ali Khan MA, et al. Cystic lung disease in Down's syndrome: a report of two cases. Pediatr Pathol 1986;5:79-86.

120 Nickerson ML, Warren MB, Toro JR, et al. Mutations in a novel gene lead to kidney tumors, lung wall defects, and benign tumors of the hair follicle in patients with the Birt-Hogg-Dube syndrome. Cancer Cell 2002;2:157-64

121 Schmidt LS, Warren MB, Nickerson ML, et al. Birt-Hogg-Dube syndrome, genodermatosis associated with spontaneous pneumothorax and kidney neoplasia, maps to chromosome 17p1 1.2. Am J Hum Genet 2001;69:876-82.

122 Kupres KA, Krivda SJ, Turiansky GW. Numerous asymptomatic facial papules and multiple pulmonary cysts: a case of Birt-Hogg-Dube syndrome. Cutis 2003;72:127-31.

\section{LUNG ALERT}

Invariant natural killer T cells in asthma and COPD: back to square one!

$\Delta$ Vijayanand P, Seumois G, Pickard C, et al. Invariant natural killer T cells in asthma and chronic obstructive pulmonary disease. N Engl J Med 2007;356:1410-22.

$\mathrm{R}$ ecent studies have suggested the possibility of invariant natural killer T cells (iNKT) playing an important role in the pathogenesis of asthma. To explore this hypothesis, the authors measured the numbers of iNKT in the airways of patients with stable mild/moderate asthma, patients with stable or exacerbated chronic obstructive pulmonary disease (COPD) and controls.

Cells from induced sputum, bronchoalveolar lavage (BAL) and/or bronchial biopsies were labelled with fluorescent monoclonal antibodies for CD3, CD4 and iNKT specific domains: V $\alpha 24$, V $\beta 11$, V $\alpha 24-J \alpha 18$ and CDId tetramers loaded with agalactosylceramide. Flow cytometry with serial gating was used for phenotyping and excluded cells other than iNKT-the failure to do so may have been a drawback of a previous study. Quantitative polymerase chain reaction to detect gene expression for $\mathrm{V} \alpha 24$ and $\mathrm{V} \beta 1 \mathrm{l}$ domains was also used.

iNKT constituted $<2 \%$ of $\mathrm{CD} 3+$ cells and $<1.5 \%$ of $\mathrm{CD} 3+/ \mathrm{CD} 4+$ cells in BAL from patients with asthma. Positive controls confirmed the accuracy of antibodies/gating strategy to detect iNKT. Similarly, very few iNKT were identified in induced sputum of controls, patients with asthma and patients with COPD with no significant differences among groups. iNKT constituted $<1.7 \%$ of CD3+ cells on biopsy analysis. BAL and sputum cells from patients with asthma and COPD did not express mRNA for $V \alpha 24$ and $V \beta 11$, despite the presence of $T$ cell receptors. This ruled out the presence of numerous iNKT among T cells and confirmed flow cytometry findings.

The authors concluded that iNKT are a minority cell population in airways of patients with asthma and COPD. The authors questioned the role of iNKT in the pathogenesis of asthma. These findings, in contrast with a recent report, suggested that future therapeutic strategies should continue to focus on class II major histocompatibility complex restricted cells.

S A Nachman Assistant Professor of Clinical Medicine, Columbia University Medical Center at Harlem Hospital, New York, NY, USA; san14@columbia.edu 